\title{
Effect of FK409, a Novel Nitric Oxide Donor, on Acute Experimental Myocardial Ischemia
}

\author{
Toyokazu Isono, Natsuki Sato, Yasushi Koibuchi, Shigeru Sakai, Takao Yamamoto, \\ Reiko Ozaki, Jo Mori, Masanobu Kohsaka and Minoru Ohtsuka* \\ Pharmacological Division, Product Development Laboratories, Fujisawa Pharmaceutical Co., Ltd., 2-1-6, Kashima, Yodogawa-ku, Osaka S32, Japan
}

Received March 2, $1993 \quad$ Accepted April 19,1993

\begin{abstract}
The anti-ischemic heart effect of $( \pm)-(E)$-4-ethyl-2-[(E)-hydroxyimino]-5-nitro-3-hexenamide (FK409), a novel nitric oxide donor, was studied in dog and rat preparations in vivo and in vitro. In anesthetized dogs with partially occluded coronary artery that were subjected to atrial pacing at a constant blood pressure, FK409 $(1-100 \mu \mathrm{g} / \mathrm{kg}$, i.v.) suppressed the ST-segment elevation on epicardial electrocardiograms. Glyceryl trinitrate (GTN; $10,32 \mu \mathrm{g} / \mathrm{kg}$ ) or dipyridamole $(1000 \mu \mathrm{g} / \mathrm{kg}$ ) failed to suppress the STsegment elevation, although continuous i.v. infusion of GTN $(32,100 \mu \mathrm{g} / \mathrm{kg} / \mathrm{min})$ was effective. FK409 also suppressed the ST-segment elevation induced by methacholine in anesthetized rats by both i.v. $(10,100$ $\mu \mathrm{g} / \mathrm{kg}$ ) and intraduodenal (i.d., 100, $1000 \mu \mathrm{g} / \mathrm{kg})$ injections, while GTN $(100 \mu \mathrm{g} / \mathrm{kg}$, i.v.; $1000 \mu \mathrm{g} / \mathrm{kg}$, i.d.) was effective only by the i.v. route. FK409 $(0.32 \mu \mathrm{g} / \mathrm{kg} / \mathrm{min}, \mathrm{i} . \mathrm{v}$. $)$ and GTN $(10 \mu \mathrm{g} / \mathrm{kg} / \mathrm{min})$ increased the blood flows of the endomyocardium (ENDO) and the epicardium (EPI) and the flow ratio of ENDO/EPI in the ischemic zone in anesthetized dogs with occluded coronary artery. Furthermore, in isolated dog vascular preparations, FK409 $\left(4.6 \times 10^{-10}-4.6 \times 10^{-7} \mathrm{M}\right)$ had a greater vasorelaxing effect on the large coronary artery $[2.0-2.5-\mathrm{mm}$ outer diameter (od)] than on the small coronary artery $(0.3-0.5-\mathrm{mm}$ od) or the saphenous artery. The results suggest that FK409 protects against acute experimental myocardial ischemia through relaxation of the large conductive coronary artery, and may be a useful oral drug for the treatment of angina pectoris.
\end{abstract}

Keywords: FK409, Myocardial ischemia, Coronary artery, Vasodilation, Nitric oxide

$( \pm)-(E)$-4-Ethyl-2-[(E)-hydroxyimino]-5-nitro-3-hexenamide (FK409, Fig. 1) is a novel semisynthetic fermentation product of Streptomyces griseosporeus with vasodilating and anti-platelet activities (1). The compound exerted a potent relaxant effect on dog and rabbit isolated arteries contracted with $\mathrm{U} 46619, \mathrm{PGF}_{2 x}, \mathrm{KCl}$, norepinephrine, histamine or 5-hydroxytryptamine (2-5); and its relaxant effect was, like that of glyceryl trinitrate (GTN) $(6,7)$, mediated through elevation of guanosine 3',5'-cyclic monophosphate (cyclic GMP) levels brought about by activation of soluble guanylate cyclase through nitric oxide formed from the FK409 molecule $(2,8)$. Furthermore, FK409 elicited less self-tolerance to its relaxant effect when compared with GTN, and it had relatively litthe cross-tolerance to organic nitrates $(2,5)$.

Thus, FK409 can be characterized as a unique vasodilator with nitric oxide-donating ability, and its ultimate

\footnotetext{
* To whom reprint requests should be addressed.
}

therapeutic utility will likely be in the treatment of myocardial ischemic diseases. We therefore carried out the present study to define its effect on acute ischemic heart models.

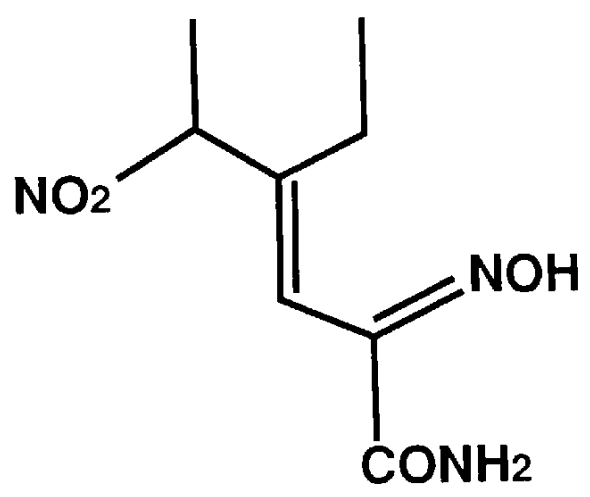

Fig. 1. Chemical structure of FK409. 


\section{MATERIALS AND METHODS}

Myocardial ischemia caused by partial occlusion of the coronary artery and atrial pacing in anesthetized dogs

The preparation was similar to that described by Szekeres et al. (9) (Fig. 2). Mongrel dogs of either sex, weighing 8.4 to $15.8 \mathrm{~kg}$, were anesthetized with pentobarbital sodium ( $35 \mathrm{mg} / \mathrm{kg}$, i.p.), and the thorax was opened under artificial respiration with room air (15-20 breaths/min). The left anterior descending coronary artery (LAD) was dissected at the origin, and a silk ligature was placed loosely around it for partial occlusion of the LAD. A flowmeter probe was also placed distal to the ligature so that no branches were present between the ligature and probe. For pacing of the heart, a bipolar silver electrode was clipped to the right auricular appendage. The parameters of the driving stimulus were as follows: dura- tion $2 \mathrm{msec}$, voltage $1-3 \mathrm{~V}$.

The myocardial ischemic changes were determined by direct monopolar epicardial leads (spiral-type, Hongo Seiki, Tokyo) with the left hind limb as the reference point. To identify the site of greatest ischemic change, three electrodes were applied simultaneously to the surface of the left anterior ventricular wall, and the electrode showing the greatest ST-segment elevation was used for evaluation (Fig. 2). Blood pressure (BP) was measured with a pressure transducer in the femoral artery, and heart rate (HR) was measured by a tachometer triggered by $\mathrm{BP}$ waves. All the parameters, including the epicardial electrocardiogram (ECG), were recorded on a polygraph (RM-85, Nihon Kohden, Tokyo).

The experimental procedure was as follows: After completing the preparation, about $60 \mathrm{~min}$ were allowed for stabilization. Then the LAD was partially occluded to
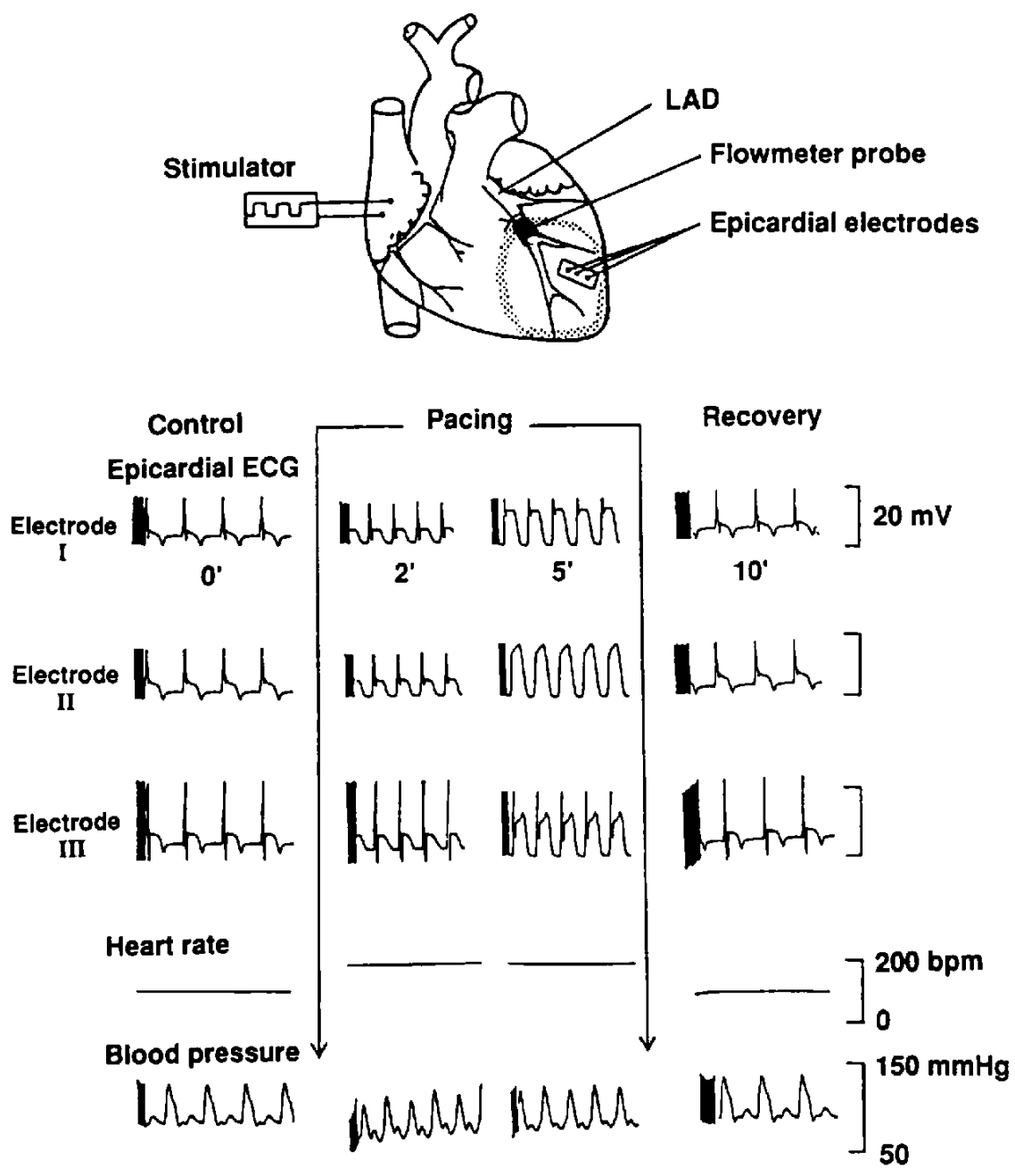

Fig. 2. Schematic diagram of the experimental method used to measure epicardial ST-segment elevation during atrial pacing in anesthetized dogs with partially occluded coronary artery. The heart was driven for $5 \mathrm{~min}$ at a rate $100 / \mathrm{min}$ higher than the basic rate 30 to $60 \mathrm{~min}$ after the partial coronary occlusion. The shaded area represents the ischemic region. LAD: left anterior descending artery. 
reduce the coronary blood flow by two-thirds of the basal flow. After the partial occlusion, a 30- to 60-min stabilization period followed. The heart was then driven for $5 \mathrm{~min}$ at a rate $100 / \mathrm{min}$ higher than the basic rate to obtain ischemic ECG changes brought about by a pacing-induced work load (Fig. 2). The test compound was given i.v. together with small doses of phenylephrine, an $\alpha$ adrenoceptor stimulant, as necessary $(2-4 \mu \mathrm{g} / \mathrm{kg}$ and/or $2-4 \mu \mathrm{g} / \mathrm{kg} / \mathrm{min}$ ) to maintain systemic BP at the pretreatment level.

\section{Regional myocardial blood flow in anesthetized dogs with coronary artery occlusion}

The study was performed according to the colored microsphere method described by Hale et al. (10). Beagle dogs of either sex, weighing 9.0 to $12.5 \mathrm{~kg}$, were anesthetized with sodium pentobarbital $(35 \mathrm{mg} / \mathrm{kg}$, i.v.) and mechanically ventilated with room air; the tidal volume was $15 \mathrm{ml} / \mathrm{kg}$ and the rate was $15 / \mathrm{min}$. The chest was then opened at the fifth left intercostal space, and the pericardium was incised. Catheters were introduced into the right femoral vein, left femoral artery and right femoral artery for drug administration, measurement of systemic BP and withdrawal of reference blood samples, respectively. Another catheter was inserted into the left atrium through the left atrial appendage for administration of microspheres. A pressure transducer-tipped catheter (PC380, Millar, Houston, TX, USA) was introduced into the left ventricle through the carotid artery for measurement of the maximum rate of rise of left ventricular pressure ( $\mathrm{LV} \max \mathrm{dp} / \mathrm{dt}$ ). The LAD was isolated proximal to the first diagonal branch for later occlusion. HR, BP and LV max dp/dt were monitored throughout the duration of the experiment.

The following experimental procedure was used: Thirty minutes after occlusion of the LAD, the test compound was administered i.v. at the rate of $0.05 \mathrm{ml} / \mathrm{kg} / \mathrm{min}$ for $30 \mathrm{~min}$. Blood flow was measured with three types of colored polystyrene microspheres $\left(12 \mu \mathrm{m}, 5 \times 10^{6}\right.$ of each; E-Z Trac, Los Angeles, CA, USA) before and at 3 and 28 min after starting drug administration. A reference blood sample was obtained at the rate of $10 \mathrm{ml} / \mathrm{min}$ starting 10 $\mathrm{sec}$ before the injection of microspheres and continuing until $80 \mathrm{sec}$ after injection (total collection time, $90 \mathrm{sec}$ ). After completion of flow measurement, the heart was removed and catheters were inserted into the LAD distal to the site of occlusion and into the aorta above the coronary ostia with the aortic valves closed. Then, the aorta and the LAD were respectively perfused with $0.25 \%$ Evans blue and saline under a constant pressure of $100 \mathrm{mmHg}$ to delineate the in vivo risk zone of ischemia. The heart was excised; tissue samples ( $2-5 \mathrm{~g}$ each) from the unstained portion (i.e., total area at risk) and the stained portion (i.e., area-not-at-risk) of the left ventricle were obtained from each dog. Processing of tissue and blood samples to quantify colored microspheres followed the method described by Hale et al. (10). Regional myocardial blood flow (RMBF, $\mathrm{ml} / \mathrm{min} / \mathrm{g}$ ) was computed with the formula: $\mathrm{RMBF}=(\mathrm{CT} \times \mathrm{R}) /(\mathrm{CR} \times \mathrm{WT})$, where $\mathrm{CT}$ is the total number of microspheres in the tissue sample, $R$ is reference flow rate $(10 \mathrm{ml} / \mathrm{min}), C R$ is the total number of microspheres in the reference blood sample, and WT is weight of the tissue sample in grams.

\section{Myocardial ischemia caused by intra-aortic injection of methacholine in anesthetized rats}

The method was essentially the same as that described by Sakai et al. (11). Male Sprague-Dawley rats weighing 338 to $425 \mathrm{~g}$ were anesthetized with ethyl carbamate (1.25 $\mathrm{g} / \mathrm{kg}, \mathrm{s.c}$.) and then intubated. For selective bolus injections of methacholine into the ostia of the coronary arteries, a polyethylene cannula was introduced through the exposed right carotid artery to a point near the aortic valve. Systemic BP and HR were measured via a pressure transducer (MPU-0.5, Nihon Kohden) in the femoral artery and a tachometer (AT601G, Nihon Kohden) triggered by BP waves respectively, and recorded on a Nihon Kohden WT-685G recorder. The standard limb lead II of the ECG was recorded by means of an electrocardiograph (ZS-501, Fukuda ME, Tokyo). The experimental procedure was as follows: After completing the preparation, about $20 \mathrm{~min}$ were allowed for stabilization. Then methacholine in doses of 4 to $8 \mu \mathrm{g}$ in a volume of $0.01 \mathrm{ml}$ were injected repeatedly into the aorta at intervals of 30 min. When reproducible ischemic ECG changes, i.e., STsegment elevations, were obtained after injections of methacholine, the test compound was given i.v. $1 \mathrm{~min}$ or intraduodenally (i.d.) $5 \mathrm{~min}$ before the next dosing with methacholine.

\section{Isolated dog and rabbit vascular preparations}

Mongrel dogs of either sex, weighing 7 to $18 \mathrm{~kg}$, were anesthetized with sodium pentobarbital $(35 \mathrm{mg} / \mathrm{kg}$, i.p.) and bled to death from the femoral artery to obtain the material for the vascular preparations. For the coronary artery, left circumflex artery (LCX, 2.0-2.5-mm outer diameter (od); large vessels) and small branches of the LAD $(0.3-0.5-\mathrm{mm}$ od, small vessels) were dissected from the myocardium and cut into spiral strips $10-15 \mathrm{~mm}$ by $0.5-1.0 \mathrm{~mm}$ for the large vessels and $5-7 \mathrm{~mm}$ by $0.2-0.5 \mathrm{~mm}$ for the small vessels. The saphenous arteries $(1.0-1.5-\mathrm{mm}$ od) were also removed and cut into spiral strips $10-15-\mathrm{mm}$ in length. The functional integrity of the endothelium was not routinely checked because FK409 as well as GTN and adenosine are known to act directly on the smooth muscle cells $(3,12,13)$. In separate 
studies with the coronary or saphenous arteries, however, the involvement of endothelium was investigated by exposing strips precontracted with $\mathrm{PGF}_{2 \alpha}(2.8 \mu \mathrm{M})$ to acetylcholine (ACh, $1 \mu \mathrm{M}$ ). In these cases, all preparations $(n=5$ each) had over $60 \%$ relaxations after application of ACh, suggesting that they contained a viable endothelium (14).

Each strip was suspended in an organ bath containing a nutrient solution at $37^{\circ} \mathrm{C}$ and gassed with $95 \% \mathrm{O}_{2}$ and $5 \%$ $\mathrm{CO}_{2}$. The tension of the strips was measured isometrically with a force-displacement transducer connected to a polygraph (RMP-6008, Nihon Kohden). The resting tension was adjusted to $60-100 \mathrm{mg}$ for the small LAD and $1.0-1.5 \mathrm{~g}$ for the other arteries. Tyrode's solution (136.9 $\mathrm{mM} \mathrm{NaCl}, 2.7 \mathrm{mM} \mathrm{KCl}, 1.8 \mathrm{mM} \mathrm{CaCl}_{2}, 1.0 \mathrm{mM} \mathrm{MgCl}$, $11.9 \mathrm{mM} \quad \mathrm{NaHCO}_{3}, \quad 0.4 \mathrm{mM} \mathrm{NaH_{2 }} \mathrm{PO}_{4}$ and $5.6 \mathrm{mM}$ dextrose) was used for the coronary preparations, and Locke's solution $(154.0 \mathrm{mM} \mathrm{NaCl}, 5.6 \mathrm{mM} \mathrm{KCl}, 2.2$ $\mathrm{mM} \mathrm{CaCl}, 6.0 \mathrm{mM} \mathrm{NaHCO}$ and $5.6 \mathrm{mM}$ dextrose) was used for the saphenous preparations. At least $1 \mathrm{hr}$ was allowed for equilibration, after which the arterial strips were contracted by $\mathrm{KCl}, 9,11$-azo- $\mathrm{PGH}_{2}\left(\right.$ azo- $\left.\mathrm{PGH}_{2}\right)$ or $\mathrm{PGF}_{2 n}$ in a concentration that caused a submaximal response (30-60 mM for $\mathrm{KCl}, 2.9-29 \mathrm{nM}$ for azo- $\mathrm{PGH}_{2}, 2.8 \mu \mathrm{M}$ for $\mathrm{PGF}_{2 \alpha}$ ). When the response to the agonist plateaued, cumulative concentrations of FK409 or other drugs were added; finally, a relaxant effect was obtained by treating each strip with a high concentration $(0.1 \mathrm{mM})$ of papaverine. The responses to the test compound were expressed as percent of the maximum relaxation caused by papaverine.

\section{Drugs}

FK409 (Fujisawa, Osaka), papaverine hydrochloride (Nacalai Tesque, Kyoto), (-)-norepinephrine hydrochloride (Sigma, St. Louis, MO, USA) and methacholine chloride (Wako Junyaku, Osaka) were dissolved in deionized water or saline before use. GTN (Nihon Kayaku, Tokyo) dissolved in ethyl alcohol (EtOH) $(10 \mathrm{mg} / \mathrm{ml})$ and dipyridamole injection (Persantin, Nippon Boehringer Ingelheim, Kawanishi) were diluted with deionized water or saline. $\mathrm{PGF}_{2 x}$ (Funakoshi, Tokyo) was dissolved in $\mathrm{EtOH}$ and then diluted with deionized water.

\section{Statistical evaluation}

The results were expressed as the mean \pm S.E.M. Statistical analyses were performed by Dunnett's multiple test for more than two-group comparison. Differences in the mean values between two groups, or the predrug and postdrug values, were assessed with Student's unpaired or paired $t$-test. Differences at the levels of $\mathrm{P}<0.05$ were considered to be significant. The $\mathrm{EC}_{50}$, the drug concentration required to produce $50 \%$ of the maximal papaverine- induced relaxation, was calculated according to the method of Litchfield and Wilcoxon.

\section{RESULTS}

Effect of FK409 on epicardial ST-segment elevation in anesthetized dogs with partial occlusion of the coronary artery and subsequent atrial pacing

As shown in Fig. 2, elevation of the ST-segment appeared within $2 \mathrm{~min}$ after pacing was started. This change increased with time, and ECG returned to the control value shortly after pacing was stopped. Therefore, pacing was maintained for $5 \mathrm{~min}$, when marked ST-segment elevation had developed, and full recovery occurred during the subsequent $5 \mathrm{~min}$ at normal $\mathrm{HR}$. The ECG change was entirely reproducible over an experimental period of approximately $90 \mathrm{~min}$, when the 5 -min atrial pacing was repeated at intervals of $30 \mathrm{~min}$ (Fig. 3, left).

FK409 in i.v.-doses of 1 to $100 \mu \mathrm{g} / \mathrm{kg}$ dose-dependently suppressed the elevation of the ST-segment under the systemic BP-controlled condition (Fig. 3, right; Table 1). In this case, increasing doses of the compound were injected at intervals of $30 \mathrm{~min}$. On the other hand, GTN failed to suppress the ST-segment elevation in i.v.-doses of 10 and $32 \mu \mathrm{g} / \mathrm{kg}$, although by continuous i.v.-infusion of 32 $\mu \mathrm{g} / \mathrm{kg} / \mathrm{min}$ or higher, it was effective, suggesting that GTN has a short-lived activity (Table 1). Dipyridamole $(1000 \% \mathrm{~g} / \mathrm{kg}$, i.v. $)$, a coronary arteriolar segment dilator, did not improve the change of the ST-segment. Phenylephrine ( $4 \mu \mathrm{g} / \mathrm{kg}+4 \mu \mathrm{g} / \mathrm{kg} / \mathrm{min}$, i.v.) also did not have any effect on the ST-segment elevation (not shown in Table 1).

Effect of FK409 on ischemic regional myocardial blood flow in anesthetized dogs

As was the case with the control (see Table 2), regional myocardial blood flow (RMBF) in the EPI and the ENDO were reduced by LAD occlusion (LV normal zone vs. LV ischemic zone). The decrease in RMBF was greater in the ENDO than in the EPI region.

In this microspheres study, FK409 was continuously injected into the vein at a constant rate (see Methods) to obtain a stable blood level of the compound during the time for collection of reference blood. The dose of 0.32 $\mu \mathrm{g} / \mathrm{kg} / \mathrm{min}$ of FK 409 was selected as a suitable infusion dose to obtain a plasma concentration of around 3 $\mathrm{ng} / \mathrm{ml}$, which was the effective plasma level of the compound in ischemic myocardial dogs with partially occluded coronary artery and subsequent atrial pacing after an i.v. bolus injection of FK409 at the dose of $10 \mu \mathrm{g} / \mathrm{kg}$ (average value at 5 to $10 \mathrm{~min}$ after injection).

FK409 at $0.32 \mu \mathrm{g} / \mathrm{kg} / \mathrm{min}$ produced significant increases in the blood flow of the ENDO and EPI, and it 


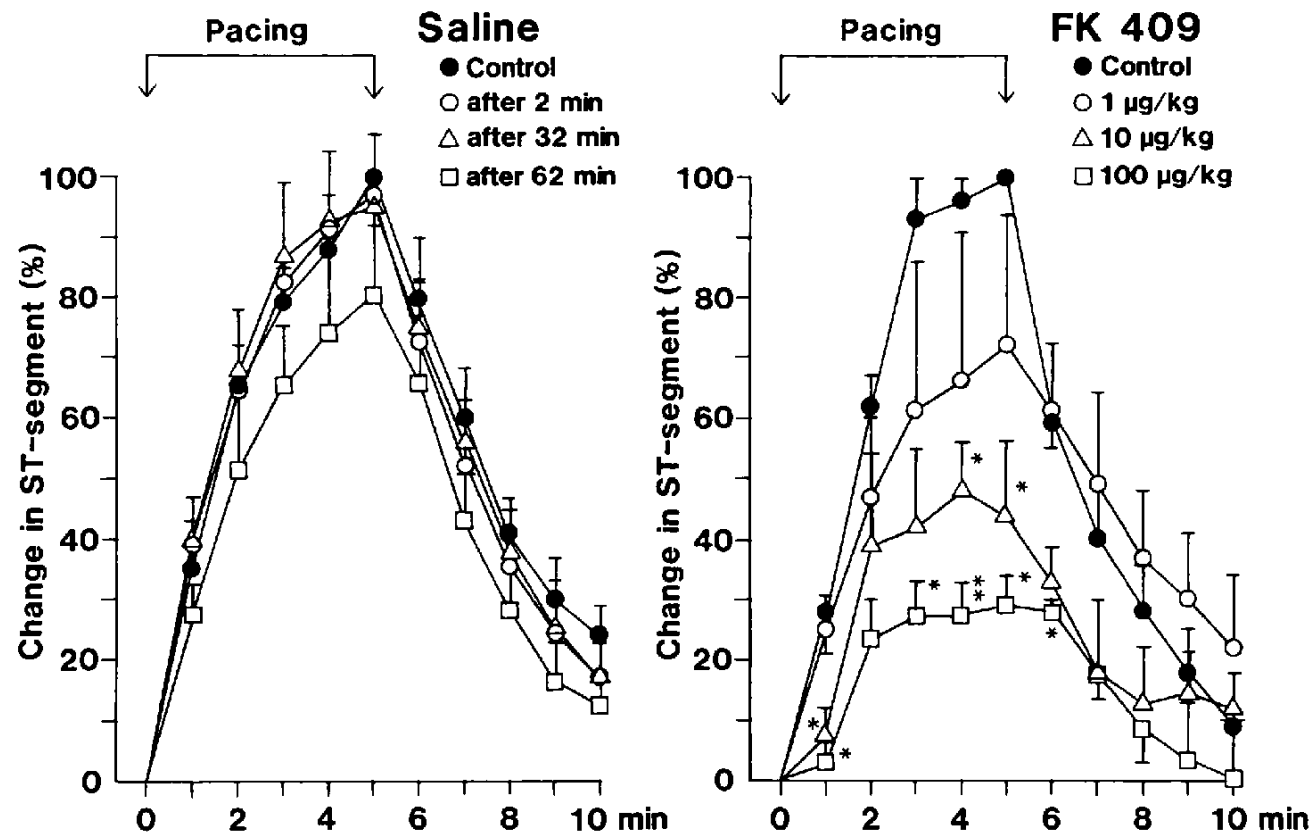

Fig. 3. Effect of FK409 on pacing-induced epicardial ST-segment elevation in anesthetized dogs with partially occluded coronary artery. All values are the means \pm S.E.M. of 3 to 5 experiments. Increasing doses of FK 409 were given into the femoral vein at intervals of $30 \mathrm{~min}$, together with small doses of phenylephrine $(2-4 \mu \mathrm{g} / \mathrm{kg}$ and $/ \mathrm{or} 2-4 \mu \mathrm{g} / \mathrm{kg} / \mathrm{min}$, i.v. $)$ to maintain systemic $\mathrm{BP}$ at the pretreatment level. ${ }^{*} \mathrm{P}<0.05,{ }^{* *} \mathrm{P}<0.01$ vs. value for control.

Table 1. Effect of FK409, GTN and dipyridamole on atrial pacing-induced epicardial ST-segment elevation in anesthetized dogs with partially occluded coronary artery

\begin{tabular}{|c|c|c|c|}
\hline \multirow{2}{*}{ Compound } & \multirow{2}{*}{ Dose (i.v.) } & \multicolumn{2}{|c|}{ Maximum elevation of the ST-segment ${ }^{a}(\mathrm{mV})$} \\
\hline & & predosing (control) & postdosing \\
\hline FK $409^{c}$ & $\begin{array}{l}1 \mu \mathrm{g} / \mathrm{kg} \\
10 \\
100\end{array}$ & $\begin{array}{l}9.4 \pm 1.1 \\
9.4 \pm 1.1 \\
9.4 \pm 1.1\end{array}$ & $\begin{array}{l}6.7 \pm 2.0 \\
4.3 \pm 1.6^{*} \\
2.8 \pm 0.8^{*}\end{array}$ \\
\hline $\mathrm{GTN}^{\mathrm{e}}$ & $10 \mu \mathrm{g} / \mathrm{kg}$ & $\begin{array}{l}7.7 \pm 1.7 \\
7.7 \pm 1.7\end{array}$ & $\begin{array}{l}7.4 \pm 2.5 \\
7.6 \pm 2.2\end{array}$ \\
\hline GTN $^{d}$ & $\begin{array}{l}32 \mu \mathrm{g} / \mathrm{kg} / \mathrm{min} \\
100\end{array}$ & $\begin{array}{r}7.4 \pm 0.9 \\
(5.8 \pm 0.8 \\
7.0 \pm 0.6\end{array}$ & $\begin{array}{l}6.0 \pm 1.1 \\
\left.3.9 \pm 1.3^{*}\right)^{e} \\
5.2 \pm 0.7^{*}\end{array}$ \\
\hline Dipyridamole & $1000 \mu \mathrm{g} / \mathrm{kg}$ & $7.3 \pm 1.6$ & $8.0 \pm 1.6$ \\
\hline
\end{tabular}

The test compound was given i.v. together with small doses of phenylephrine, an $\alpha-$ adrenoceptor stimulant, to animals as necessary (2-4 $\mu \mathrm{g} / \mathrm{kg}$ and $/$ or $2-4 \mu \mathrm{g} / \mathrm{kg} / \mathrm{min}$ ) to maintain BP at the control level. Phenylephrine in doses of $2-4 \mu \mathrm{g} / \mathrm{kg}$ or $2-4$ $\mu \mathrm{g} / \mathrm{kg} / \mathrm{min}$ did not have any significant effect. Values are the mean \pm S.E.M. of $3-5 \mathrm{ex}-$ periments. ${ }^{*} \mathbf{P}<0.05$ vs. value for control. GTN, Glyceryl trinitrate. ${ }^{2}$ the value at $5 \mathrm{~min}$ after starting the pacing. ${ }^{\mathrm{b}} 2 \mathrm{~min}$ after i.v. bolus administration or $5 \mathrm{~min}$ after starting the i.v. infusion. ${ }^{c}$ increasing doses. ${ }^{d} \mathrm{i} . \mathrm{v}$. infusion for $10 \mathrm{~min}(\mu \mathrm{g} / \mathrm{kg} / \mathrm{min}) .{ }^{e}$ the submaximal elevation at $3 \mathrm{~min}$ after starting the pacing.

also increased the ratio of ENDO/EPI in the ischemic zone at both the 3-and 28-min time points (Table 2). On the other hand, there were no significant changes in any RMBF of the normal zone (Table 2) or in other cardiovascular parameters including BP (Table 3) during FK409 in- fusion. GTN at $10 \mu \mathrm{g} / \mathrm{kg} / \mathrm{min}$ had a similar effect (Table 2 ), but $32 \mu \mathrm{g} / \mathrm{kg} / \mathrm{min}$ caused severe hypotension (mean BP: $-18 \pm 1 \mathrm{mmHg}$ at $5 \mathrm{~min}$ after starting the i.v.-infusion, $n=3$ ), and its effect could not be evaluated. 
Table 2. Effect of intravenous FK409 and GTN on regional myocardial blood flow in normal and ischemic zones during acute coronary occlusion

\begin{tabular}{|c|c|c|c|c|c|c|}
\hline \multirow[b]{2}{*}{ Region } & \multicolumn{3}{|c|}{3 min after starting compound i.v. infusion } & \multicolumn{3}{|c|}{28 min after starting compound i.v. infusion } \\
\hline & $\begin{array}{l}\text { Control } \\
\text { (saline) }\end{array}$ & $\begin{array}{c}\mathrm{FK} 409 \\
(0.32 / \mathrm{g} / \mathrm{kg} / \mathrm{min})\end{array}$ & $\begin{array}{c}\mathrm{GTN} \\
(10 \mu \mathrm{g} / \mathrm{kg} / \mathrm{min})\end{array}$ & $\begin{array}{l}\text { Control } \\
\text { (saline) }\end{array}$ & $\begin{array}{c}\text { FK } 409 \\
(0.32 \mu \mathrm{g} / \mathrm{kg} / \mathrm{min})\end{array}$ & $\begin{array}{c}\mathrm{GTN} \\
(10 \mu \mathrm{g} / \mathrm{kg} / \mathrm{min})\end{array}$ \\
\hline \multicolumn{7}{|l|}{ LV normal zone } \\
\hline ENDO $(\mathrm{ml} / \mathrm{g} / \mathrm{min})$ & $0.85 \pm 0.11$ & $0.88 \pm 0.08$ & $0.82 \pm 0.05$ & $0.83 \pm 0.03$ & $0.88 \pm 0.08$ & $0.73 \pm 0.03$ \\
\hline $\mathrm{EPI}(\mathrm{ml} / \mathrm{g} / \mathrm{min})$ & $0.86 \pm 0.13$ & $0.86 \pm 0.11$ & $0.79 \pm 0.05$ & $0.89 \pm 0.10$ & $0.82 \pm 0.08$ & $0.85 \pm 0.06$ \\
\hline ENDO/EPI & $1.01 \pm 0.05$ & $1.17 \pm 0.30$ & $1.05 \pm 0.09$ & $0.97 \pm 0.10$ & $1.08 \pm 0.04$ & $0.89 \pm 0.08$ \\
\hline \multicolumn{7}{|l|}{ LV ischemic zone } \\
\hline ENDO $(\mathrm{ml} / \mathrm{g} / \mathrm{min})$ & $0.12 \pm 0.01$ & $0.22 \pm 0.01^{* * *}$ & $0.19 \pm 0.02^{* *}$ & $0.13 \pm 0.01$ & $0.25 \pm 0.01^{* *}$ & $0.27 \pm 0.03^{*}$ \\
\hline $\mathrm{EPI}(\mathrm{ml} / \mathrm{g} / \mathrm{min})$ & $0.25 \pm 0.02$ & $0.35 \pm 0.03^{*}$ & $0.30 \pm 0.02$ & $0.24 \pm 0.02$ & $0.33 \pm 0.02^{*}$ & $0.34 \pm 0.02^{* *}$ \\
\hline ENDO/EPI & $0.48 \pm 0.02$ & $0.66 \pm 0.05^{* *}$ & $0.61 \pm 0.03^{*}$ & $0.56 \pm 0.04$ & $0.77 \pm 0.03^{* *}$ & $0.80 \pm 0.07^{*}$ \\
\hline
\end{tabular}

The blood flow was measured with the colored microsphere method (10). Intravenous infusion of FK409 or GTN was started 30 min after LAD occlusion. Values are the mean \pm S.E.M. of 4-5 experiments. GTN, Glyceryl trinitrate, LV, left ventricle; ENDO, endocardium; EPI, epicardium; ENDO/EPI, endocardial-to-epicardial blood flow ratio. ${ }^{*} \mathrm{P}<0.05,{ }^{* *} \mathrm{P}<0.01$ vs. value for control.

Table 3. Effects of intravenous FK409 and GTN on mean blood pressure, heart rate and the maximum rate of rise of left ventricular pressure (LV max dp/dt) during acute coronary occlusion

\begin{tabular}{|c|c|c|c|c|c|c|}
\hline \multirow[b]{2}{*}{ Parameter } & \multicolumn{3}{|c|}{$3 \mathrm{~min}$ after starting compound i.v. infusion } & \multicolumn{3}{|c|}{28 min after starting compound i.v. infusion } \\
\hline & $\begin{array}{l}\text { Control } \\
\text { (saline) }\end{array}$ & $\begin{array}{c}\text { FK409 } \\
(0.32 \mu \mathrm{g} / \mathrm{kg} / \mathrm{min})\end{array}$ & $\begin{array}{c}\mathrm{GTN} \\
(10 \mu \mathrm{g} / \mathrm{kg} / \mathrm{min})\end{array}$ & $\begin{array}{l}\text { Control } \\
\text { (saline) }\end{array}$ & $\begin{array}{c}\text { FK409 } \\
(0.32 \mu \mathrm{g} / \mathrm{kg} / \mathrm{min})\end{array}$ & $\begin{array}{c}\mathrm{GTN} \\
(10 \mu \mathrm{g} / \mathrm{kg} / \mathrm{min})\end{array}$ \\
\hline Heart rate (beats/min) & $126 \pm 12$ & $106 \pm 9$ & $119 \pm 14$ & $124 \pm 11$ & $103 \pm 9$ & $110 \pm 13$ \\
\hline $\mathrm{LV} \max \mathrm{dp} / \mathrm{dt}(\mathrm{mmHg} / \mathrm{sec})$ & $1644 \pm 278$ & $1480 \pm 201$ & $1775 \pm 284$ & $1634 \pm 253$ & $1348 \pm 135$ & $1675 \pm 284$ \\
\hline
\end{tabular}

Intravenous infusion with FK409 or GTN was started 30 min after LAD occlusion. Values are the mean \pm S.E.M. of 4-5 experiments. GTN, Glyceryl trinitrate; LV, left ventricle. There were no significant changes in the parameters between the control and FK409 or GTN (P>0.05).

\section{Effect of FK409 on ST-segment elevation caused by intra-} aortic injection of methacholine in anesthetized rats

Methacholine in intra-aortic doses of 4 to $8 \mu \mathrm{g}$ evoked a transient hypotension, followed thereafter by marked elevation of the ST-segment and the $T$ wave of the ECG, in accordance with the previous findings $(11,15)$. These ECG changes lasted 10 to $30 \mathrm{sec}$ and were reproducible 4 to 6 times at injection intervals of $30 \mathrm{~min}$.

FK409 in i.v.-doses of 10 and $100 \mu \mathrm{g} / \mathrm{kg}$ suppressed the elevation of the ST-segment ( $P<0.01$ or 0.05 ; Fig. 4, upper graph). GTN at $100 \mu \mathrm{g} / \mathrm{kg}$ also was effective, and its $\%$ inhibition was almost comparable to that of FK409 at $10 \mu \mathrm{g} / \mathrm{kg}(41 \%$ vs. $42 \%)$. On the other hand, i.d. administration of FK409 was effective in doses of more than 100 $\mu \mathrm{g} / \mathrm{kg}$, about 10 times the i.v. effective dose, whereas GTN had no effect in an i.d. dose of $1000 / \mathrm{g} / \mathrm{kg}$ (Fig. 4, lower graph). These results indicate that FK409 has a more potent suppressing effect than GTN and exerts a therapeutic effect after absorption from the intestinal tract.

\section{Effect of FK409 on isolated dog coronary and saphenous arteries}

As shown in Fig. 5, FK409 in concentrations of $4.6 \times$ $10^{-10} \mathrm{M}$ and higher had dose-dependent relaxant effects on $\mathrm{KCl}$ - or azo- $\mathrm{PGH}_{2}$, a stable thromboxane $\mathrm{A}_{2}$ agonist (16), -induced contractions of the coronary (large vessel, 2.0-2.5-mm od) and saphenous arteries. The vasorelaxing effect of FK409, however, differed in the two arteries; the action of the compound was greater on the coronary artery than on the saphenous artery, with approximately a 150-fold difference between their $\mathrm{EC}_{50}$ values: $\mathrm{KCl}$-contracture, $(6.2 \pm 1.3) \times 10^{-9} \mathrm{M}$ for coronary artery vs. $(9.0 \pm 5.7) \times 10^{-7} \mathrm{M}$ for saphenous artery; azo- $\mathrm{PGH}_{2-}$ contracture, $(3.9 \pm 0.9) \times 10^{-9} \mathrm{M}$ for coronary artery vs. $(5.9 \pm 2.4) \times 10^{-7} \mathrm{M}$ for saphenous artery.

Similar results were observed in isolated dog coronary and saphenous arteries contracted with $\mathrm{PGF}_{2 \alpha}$ (not shown in Fig. 5): $\mathrm{EC}_{50}$ values, $(3.2 \pm 0.3) \times 10^{-9} \mathrm{M}$ for coronary artery vs. $(3.1 \pm 0.6) \times 10^{-8} \mathrm{M}$ for saphenous artery, $\mathrm{P}<0.01, \mathrm{n}=6$ each. 
[i.v. administration ]
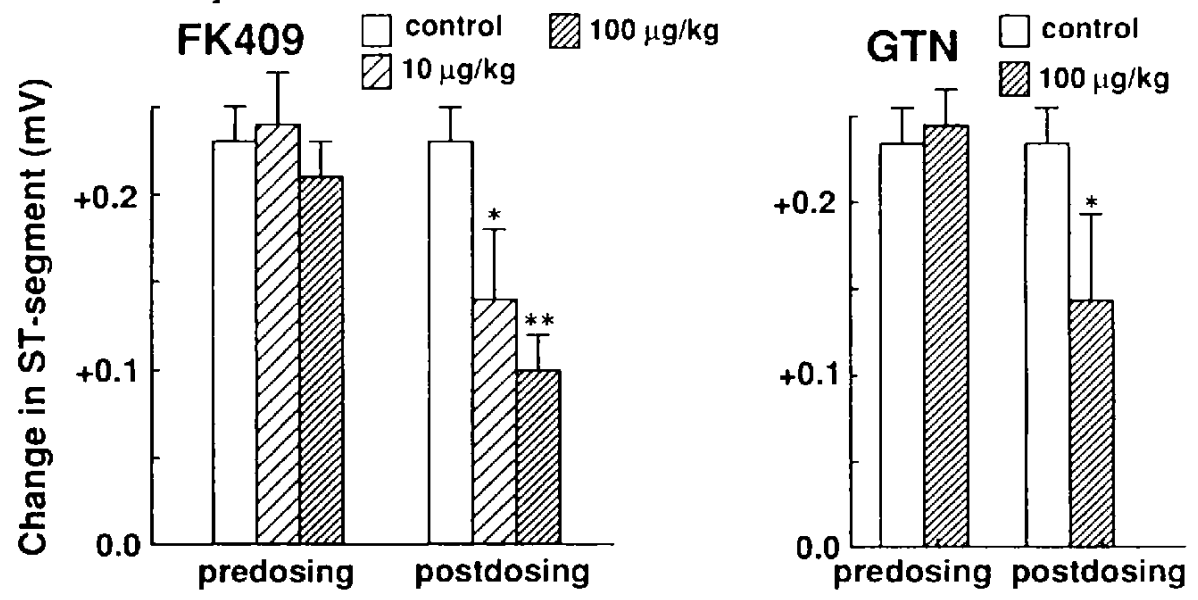

[i.d. administration ]
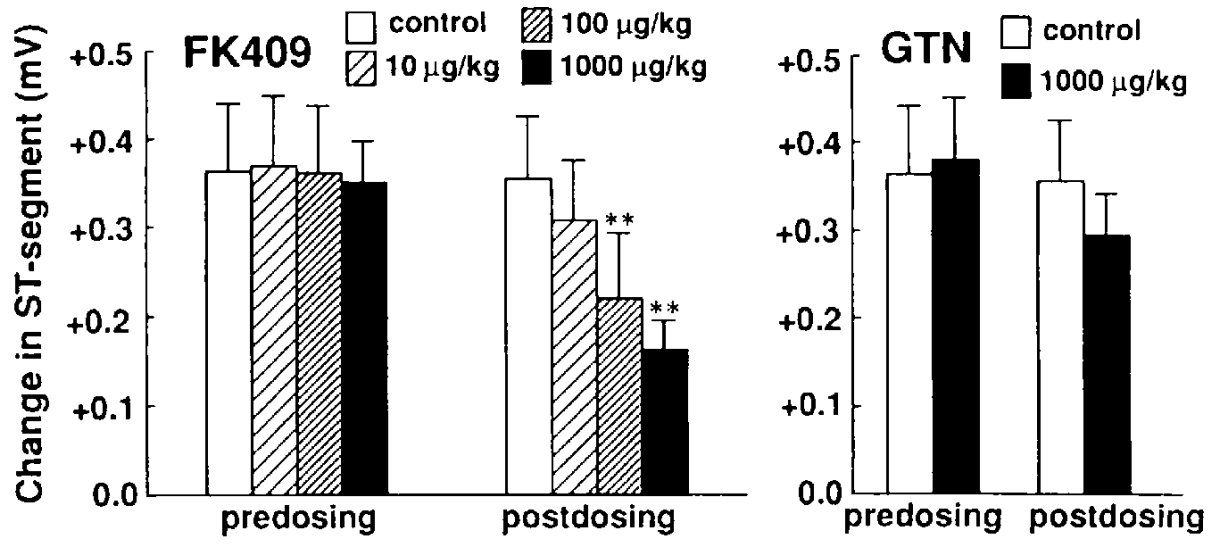

Fig. 4. Effects of FK409 and glyceryl trinitrate (GTN) on methacholine-induced ST-segment elevation in anesthetized rats. All values are the means \pm S.E.M. of 6 to 12 experiments. The test compounds were given i.v. 1 min or intraduodenally (i.d.) 5 min before dosing with methacholine. ${ }^{*} \mathrm{P}<0.05,{ }^{* *} \mathrm{P}<0.01$ vs. value for predosing.
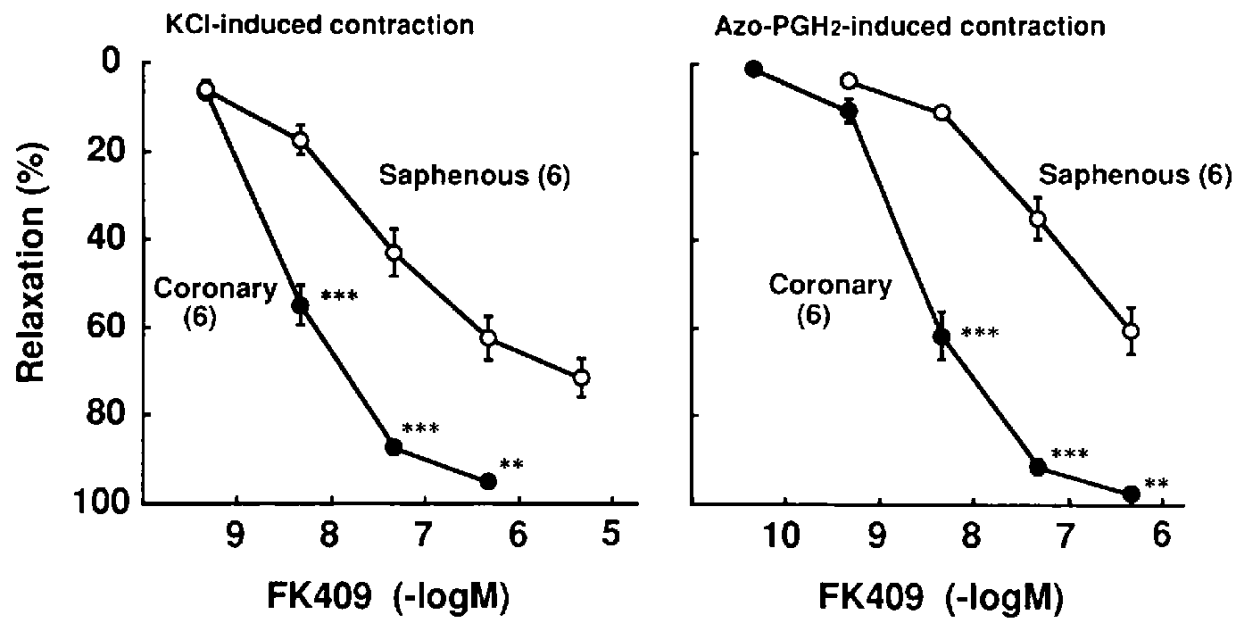

Fig. 5. Relaxation caused by $\mathrm{FK} 409$ in $\mathrm{KCl}$ or azo-PGH 2 -induced contractions of dog coronary and saphenous arteries. Relaxation at $0.1 \mathrm{mM}$ papaverine was taken as $100 \%$. Means \pm S.E.M. are presented. Figures in parentheses indicate the number of preparations used. ${ }^{* *} \mathrm{P}<0.01,{ }^{* * *} \mathrm{P}<0.001$ vs. value for the saphenous artery. 
Table 4. Vasorelaxing effect of FK409 and GTN in isolated dog coronary (large vessel) arterial preparations

\begin{tabular}{|c|c|c|}
\hline \multirow{2}{*}{ Agonist } & \multicolumn{2}{|c|}{$\mathrm{EC}_{50}(\mathrm{M})$} \\
\hline & FK409 & GTN \\
\hline $35 \mathrm{mM} \mathrm{KCl}$ & $(6.2 \pm 1.3) \times 10^{-9 *}$ & $(1.6 \pm 0.5) \times 10^{-7}[1 / 26]$ \\
\hline $29 \mathrm{nM}$ azo-PGH & $(3.9 \pm 0.9) \times 10^{-9 * * *}$ & $(2.5 \pm 0.3) \times 10^{-8}[1 / 6]$ \\
\hline $2.8 \mu \mathrm{M} \mathrm{PGF}_{2 \alpha}$ & $(3.2 \pm 0.3) \times 10^{-9 *}$ & $(1.6 \pm 0.5) \times 10^{-8}[1 / 5]$ \\
\hline
\end{tabular}

Values are the means \pm S.E.M. of 6 experiments. GTN, Glyceryl trinitrate. ${ }^{*} \mathrm{P}<0.05,{ }^{* * *} \mathbf{P}<0.001$ vs. value for GTN. [ ]: potency relative to that for FK409. Large vessel: left circumflex artery with $2.0-2.5-\mathrm{mm}$ outer diameter.

The coronary vasorelaxing activities of FK 409 were 5 to 26 times more effective than those of GTN (Table 4).

\section{Comparative effect of FK409 on isolated dog large and small coronary arteries}

The coronary vasorelaxing activity of FK409 was additionally examined in the vessels with small $(0.3-0.5-\mathrm{mm}$ od) and large $(2.0-2.5-\mathrm{mm}$ od) diameters by the method of Schnaar and Sparks (17). Since the responses of large and small vessels to a compound could not be directly compared because the small vessel, having less cross-sectional area, could not exhibit absolute tension changes as great as those of the large vessel, they were expressed as a percent of vessel relaxation after treatment with papaverine hydrochloride.

As shown in Fig. 6, FK409 had a more potent effect on the large vessels than on the small ones of the coronary arteries contracted by $\mathrm{KCl}$. The $\mathrm{EC}_{50}$ values of the compound for the large and small arteries were $(6.2 \pm 1.3)$ $\times 10^{-9} \mathrm{M}$ and $(2.0 \pm 0.7) \times 10^{-7} \mathrm{M}$, respectively, with a difference of approximately 30 -fold between the values $(\mathrm{P}<0.05)$. GTN also had a selective activity for the large vessels: $\mathrm{EC}_{50},(1.6 \pm 0.5) \times 10^{-7} \mathrm{M}$ for the large artery, $(1.8 \pm 0.6) \times 10^{-6} \mathrm{M}$ for the small artery; $\mathrm{EC}_{50}$ ratio of small/large, $11 ; n=6$ each. In contrast, adenosine was rather more active on the small artery: $\mathrm{EC}_{50},>3.7 \times 10^{-4}$ $\mathrm{M}$ for the large artery, $(1.1 \pm 0.4) \times 10^{-4} \mathrm{M}$ for the small artery; ratio, $<0.3 ; n=6$ each; Fig. 6 .

A similar large vessel-selective effect of FK409 was observed with coronary arteries contracted by either azo$\mathrm{PGH}_{2}$ (not shown in Fig. 6): $\mathrm{EC}_{50},(3.9 \pm 0.9) \times 10^{-9} \mathrm{M}$ for the large artery, $(2.4 \pm 1.4) \times 10^{-8} \mathrm{M}$ for the small artery, $\mathrm{n}=6$ each or $\mathrm{PGF}_{2 \alpha}: \mathrm{EC}_{50},(3.2 \pm 0.3) \times 10^{-9} \mathrm{M}$ for the large artery, $(1.3 \pm 0.3) \times 10^{-8} \mathrm{M}$ for the small artery, $\mathrm{n}=6$ each, $\mathrm{P}<0.01$.

\section{DISCUSSION}

The present findings with ischemic heart models suggest that FK409 will produce a therapeutic effect on ischemic heart diseases; i.e., the compound in i.v. bolus doses of 1 to $100 \mu \mathrm{g} / \mathrm{kg}$ was effective in suppressing epicardial STsegment elevations in anesthetized dogs with partial occlusion of the coronary artery and subsequent atrial pacing. In this experiment, BP was controlled at a constant level to avoid disturbance of the coronary action of the compound due to hypotension. This ischemic heart model mimics, in certain aspects at least, the alterations in myocardial oxygen demand and supply in classical angina pectoris, and it has been reported to be useful for the evaluation of potential antianginal drugs $(9,18)$. Using a similar model, Szekeres et al. (9) found that a 10-min i.v.
FK409

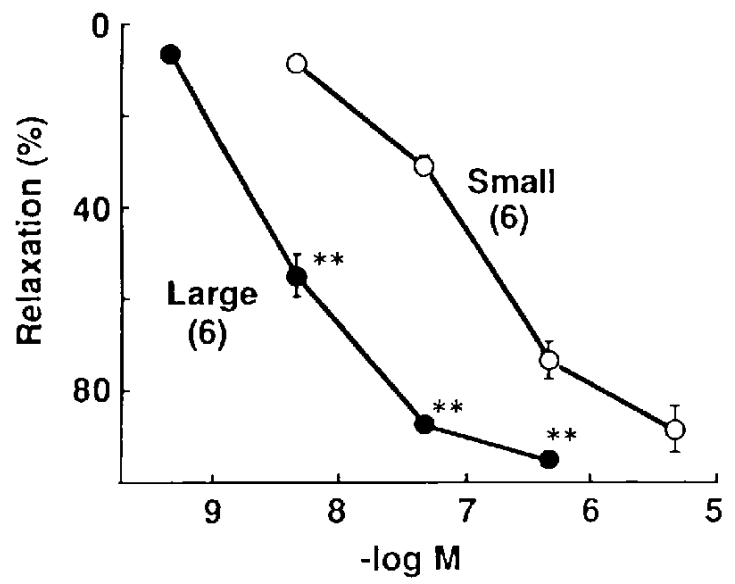

Adenosine

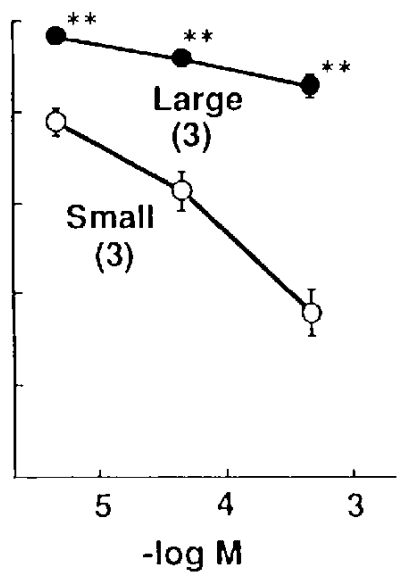

Fig. 6. Relaxing responses of large $(2.0-2.5-\mathrm{mm}$ od) and small $(0.3-0.5-\mathrm{mm}$ od) coronary arteries to FK409 and adenosine. The vessels were contracted by $35 \mathrm{mM} \mathrm{KCl}$. Relaxation at $0.1 \mathrm{mM}$ papaverine was taken as $100 \%$. Means $\pm \mathrm{S}$.E. M. are presented. Figures in parentheses indicate the number of preparations used. ${ }^{* *} \mathrm{P}<0.01$ vs. value for the small vessel. 
infusion of GTN at $20 \mu \mathrm{g} / \mathrm{kg}$ reduced the epicardial STsegment and $\mathrm{T}$-wave elevations, whereas dipyridamole, a potent coronary arteriolar segment dilator, at $60 \mu \mathrm{g} / \mathrm{kg}$ failed to do this. Our findings for GTN and dipyridamole (Table 1) were in good agreement with those of Szekeres et al. In addition, FK409 was effective in suppressing the elevation of the ST-segment induced by methacholine in anesthetized rats (Fig. 4). This suppressing effect cannot be attributed to an antagonistic action toward vascular muscarinic receptors, because the compound has no anticholinergic activity (M. Ohtsuka et al., unpublished data). Sakai et al. (11) first reported that a single dose of methacholine, a cholinomimetic drug, administered intraarterially evokes a marked elevation of the ST-segment and $\mathrm{T}$-wave of the ECG in intact anesthetized rats, and suggested that the ECG changes induced by methacholine can be ascribed to coronary vasoconstriction, indicating severe myocardial anoxia or ischemia. This phenomenon in rats resembles the clinical sequelae of a certain type of angina pectoris $(19,20)$, and it was also reported that cholinomimetic drugs such as methacholine or pilocarpine are capable of producing a coronary arterial spasm corresponding to the ST-segment elevation in patients with variant angina (21).

It is noteworthy that FK409 was intraduodenally active, whereas this was not the case with GTN. The difference in their suppressing effects on methacholine-induced ECG changes after i.d.-administration is probably due to a difference in their absorption from the intestinal tract or in their first-pass extraction in animals, as the doses of FK409 and GTN we used were based on their in vitro vasorelaxing activities (2-5). GTN is well known to be degraded during its first pass through the liver.

According to the present studies on vascular muscle preparations, the anti-ischemic heart effect of FK409 is highly likely to be due to its distinctive coronary vasorelaxant action. In our in vitro studies on isolated dog vascular strips, FK409 had a greater vasorelaxing activity on the coronary artery than on the saphenous artery; and moreover, its coronary activity was greater on the large vessels $(2.0-2.5-\mathrm{mm}$ od) than on the small ones $(0.3-0.5$ $\mathrm{mm}$ od). This effect was entirely the opposite that of adenosine, a putative coronary metabolic vasodilator. The large coronary-selectivity of FK409 was rather superior to that of GTN, and its potency of activity was 5 to 26 times greater (Table 4). Fam and McGregor (22) and Winbury et al. (23) have demonstrated that GTN acts preferentially on the large coronary arteries in in situ studies with dogs and suggested that this results in increased blood flow to the ischemic region of the myocardium, and may be related to the anti-anginal effect of the drug. Schnaar and Sparks (17) further studied this possibility by examining the relaxing effect of GTN on the isolated vascular smooth muscle from large (2-mm od) and small (550- $\mu \mathrm{m}$ od) coronary arteries of dogs, and confirmed the in situ work suggesting differences in the responses of the vascular smooth muscle of the large and small coronary arteries to GTN. They also found that adenosine causes greater relaxation of the small vessels than the large vessels (17), which is in agreement with our in vitro data for adenosine. Thus, from the present in vitro findings, FK409 is expected to facilitate redistribution of the blood to the ischemic region of the myocardium due to relaxation of the conductive large coronary vessels or collateral vessels.

In fact, FK 409 produced a favorable redistribution of myocardial blood flow in the present in vivo study (Table 2). In this study, an i.v.-infusion dose $(0.32 \mu \mathrm{g} / \mathrm{kg} / \mathrm{min})$ was used to obtain a stable plasma concentration of around $3 \mathrm{ng} / \mathrm{ml}$, which was the effective level in the present ischemic heart models after i.v. bolus injection of FK409 at $10 \mu \mathrm{g} / \mathrm{kg}$. This infusion dose produced no significant effects on BP, HR or LV max $\mathrm{dp} / \mathrm{dt}$. Increased myocardial blood flow in the ischemic region theoretically depends on the drug action on large conductance coronary arteries and collateral vessels rather than on direct effects at the arteriolar level (22). In this case, FK409 was administered after a 30 -min stabilization period. As it has been reported that most of the flow increase due to opening of endogenous collateral vessels occurred during the first 5 to $10 \mathrm{~min}$ after coronary occlusion in dogs and that ischemic flow was stable during the next several hours (24), it is probable that the compound effects in the present study were upon a stable endogenous collateral system.

Thus, one possible explanation for the anti-ischemic heart effect of FK409 might be its distinctive coronary vasodilating activity. However, it has been reported that FK409 decreased venous return in anesthetized dogs when measured as a sum of the flow through the inferior and the superior vena cava (25), suggesting that the compound also may improve myocardial ischemia through a reduction of cardiac preload.

Yamada et al. (2) reported that the concentrationvasorelaxation curve for FK409 was shifted to the right by methylene blue, an inhibitor of soluble guanylate cyclase, and to the left by M\&B 22,948, an inhibitor of cyclic GMP phosphodiesterase. FK409 also produced an increase in cyclic GMP levels associated with a vasorelaxation in isolated dog coronary arteries (2) and isolated rat aortas (8). In addition, it has been reported that the compound released nitric oxide and activated soluble guanylate cyclase even in the absence of SH groups (8). Therefore, it is highly likely that the vasorelaxant effect of FK409 is due to cyclic GMP accumulation. The large coronary selectivity of FK409 may be derived from the 
regional difference in cyclic GMP accumulation, although further studies are needed to clarify the detailed mechanisms of vascular selectivity of the compound.

In summary, our in vivo and in vitro studies demonstrated that FK409 suppresses ischemic ECG changes in anesthetized animals, and this suppressive effect is likely to be due to the compound's strong large coronary arteryselective vasorelaxant action. However, other pharmacological actions, such as reduction of cardiac preload, would be possible as additional mechanisms for the antiischemic heart effect of the compound.

\section{Acknowledgments}

We would like to thank Atsuko Furuichi, Shunji Yamazaki, Tadashi Sawada, Shintaro Miura and Misako Nishii for their excellent technical assistance.

\section{REFERENCES}

1 Hino, M., Iwami, M., Okamoto, M., Yoshida, K., Haruta, H., Okuhara, M., Hosoda, J., Kohsaka, M., Aoki, H. and Imanaka, H.: FK409, a novel vasodilator isolated from the acidtreated fermentation broth of Streptomyces griseosporeus. I. Taxonomy, fermentation, isolation, and physico-chemical and biological characteristics. J. Antibiot. (Tokyo) 42, 1578-1583 (1989)

2 Yamada, H., Yoneyama, F., Satoh, K. and Taira, N.: Comparison of the effects of the novel vasodilator FK409 with those of nitroglycerin in isolated coronary artery of the dog. Br. J. Pharmacol. 103, 1713-1718 (1991)

3 Shibata, S., Satake, N., Sato, N., Matsuo, M., Koibuchi, Y. and Hester, R.K.: Characteristics of the vasorelaxing action of (3E)-4-ethyl-2-hydroximino-5-nitro-3-hexamide FK409, a new vasodilator isolated from microbial sources, in isolated rabbit arteries. J. Cardiovasc. Pharmacol. 17, $508-518$ (1991)

4 Ohtsuka, M., Koibuchi, Y., Sakai, S., Sato, N., Isono, T., Sudo, Y., Ono, T., Mori, J. and Shibayama, F.: Cardiovascular activity of FK409, a new drug for ischemic heart diseases, on dog in vitro and in vivo preparations. Eur. J. Pharmacol. 183, $1292-1293$ (1990)

5 Sato, N., Ohtsuka, M., Koibuchi, Y., Sakai, S., Isono, T., Sudo, Y., Ono, T., Mori, J. and Shibayama, F.: Cardiovascular profile of FR900409, a newly synthesized vasodilator, in isolated dog vascular preparations and in anesthetized dogs and rats. Japan. J. Pharmacol. 52, Supp. I, 218P (1990)

6 Feelisch, M. and Noack, E.A.: Correlation between nitric oxide formation during degradation of organic nitrates and activation of guanylate cyclase. Eur. J. Pharmacol. 139, 19-30 (1987)

7 Kukovetz, W.R., Holzmann, S. and Poch, B.: Evidence for cyclic GMP-mediated relaxant effects of nitro-compounds in coronary smooth muscle. Naunyn Schmiedebergs Arch. Pharmacol. 310, 129-138 (1979)

8 Sato, N., Nishii, M., Uejima, A., Ohtsuka, M., Mori, J. and Kohsaka, M.: FK409-induced vasorelaxation: the role of nitric oxide (NO). Japan. J. Pharmacol. 58, Supp. I, 287P (1992)

9 Szekeres, L., Csik, V. and Udvary, É.: Nitroglycerin and dipyridamole on cardiac metabolism and dynamics in a new experimental model of angina pectoris. J. Pharmacol. Exp. Ther.
196, 15-28 (1976)

10 Hale, S.L., Alker, K.J. and Kloner, R.A.: Evaluation of nonradioactive, colored microspheres for measurement of regional myocardial blood flow in dogs. Circulation 78, $428-434$ (1988)

11 Sakai, K., Akima, M. and Aono, J.: Evaluation of drug effects in a new experimental model of angina pectoris in the intact anesthetized rat. J. Pharmacol. Methods 5, 325-336 (1981)

12 Furchgott, R.F., Zawadzki, J.V. and Cherry, P.D.: Role of endothelium in the vasodilator response to acetylcholine. In Vasodilatation, Edited by Vanhoutte, P.M. and Leusen, I, pp. 49-66, Raven Press, New York (1981)

13 White, T.D. and Angus, J.A.: Relaxant effects of ATP and adenosine on canine large and small coronary arteries in vitro. Eur. J. Pharmacol. 143, 119-126 (1987)

14 Furchgott, R.F. and Zawadzki, J.V.: The obligatory role of endothelial cells in the relaxation of arterial smooth muscle by acetylcholine. Nature 288, 373-376 (1980)

15 Aono, J., Akima, M. and Sakai, K.: Effects of N-(2-hydroxyethyl) nicotinamide nitrate (SG-75) on methacholine-induced ECG changes in intact anesthetized rats. Japan. J. Pharmacol. 31, 823-830 (1981)

16 Corey, E.J., Nicolaou, K.C., Machida, Y., Malmsten, C.L. and Samuelsson, B.: Synthesis and biological properties of a 9,11-azo-prostanoid: Highly active biochemical mimic of prostaglandin endoperoxides. Proc. Natl. Acad. Sci. U.S.A. 72, 3355-3358 (1975)

17 Schnaar, R.L. and Sparks, H.V.: Response of large and small coronary arteries to nitroglycerin, $\mathrm{NaNO}_{2}$, and adenosine. Am. J. Physiol. 223, 223-228 (1972)

18 Csik, V., Szekeres, L. and Udvary, E.: Comparison of two calcium antagonists, verapamil and fendiline, in an experimental model of myocardial ischaemia mimicking classical angina on effort. Br. J. Pharmacol. 79, 37-43 (1983)

19 De Servi, S., Specchia, G. and Angoli, L.: Coronary artery spasm of different degrees as cause of angina at rest with ST segment depression and elevation. Br. Heart J. 42, 110-112 (1979)

20 Maseri, A., L'Abbate, A., Chierchia, S., Parodi, O., Severi, S., Distante, A., Marzilli, M. and Ballestra, L.M.: Significance of spasm in the pathogenesis of ischemic heart disease. Am. J. Cardiol. 44, 788-792 (1979)

21 Endo, M., Hirosawa, K., Kaneko, N., Hase, K., Inoue, Y. and Konno, S.: Prinzmetal's variant angina: Coronary arteriogram and left ventriculogram during angina attack induced by methacholine. N. Engl. J. Med. 29, 252-255 (1976)

22 Fam, W.M. and McGregor, M.: Effect of nitroglycerin and dipyridamole on regional coronary resistance. Circ. Res. 22, $649-659(1968)$

23 Winbury, M.M., Howe, B.B. and Hefner, M.A.: Effect of nitrates and other coronary dilators on large and small coronary vessels: An hypothesis for the mechanism of action of nitrates. J. Pharmacol. Exp. Ther. 168, 70-95 (1969)

24 Hirzel, H.O., Nelson, G.R., Sonnenblick, E.H. and Kirk, E.S.: Redistribution of collateral blood flow from necrotic to surviving myocardium following coronary occlusion in the dog. Circ. Res. 39, 214-222 (1976)

25 Yamada, H., Yoneyama, F., Satoh, K. and Taira, N.: Cardiohemodynamic effect of FK409, a novel highly potent nitrovasodilator, in anesthetized dogs. Eur. J. Pharmacol. 205, $81-83$ (1991) 